\title{
Patient, physician, encounter, and billing characteristics predict the accuracy of syndromic surveillance case definitions
}

\author{
Geneviève Cadieux ${ }^{1 *}$, David L Buckeridge ${ }^{1,2 \dagger}$, André Jacques ${ }^{3 \dagger}$, Michael Libman ${ }^{4 \dagger}$, Nandini Dendukuri ${ }^{1 \dagger}$ and \\ Robyn Tamblyn ${ }^{1,4+}$
}

\begin{abstract}
Background: Syndromic surveillance systems are plagued by high false-positive rates. In chronic disease monitoring, investigators have identified several factors that predict the accuracy of case definitions based on diagnoses in administrative data, and some have even incorporated these predictors into novel case detection methods, resulting in a significant improvement in case definition accuracy. Based on findings from these studies, we sought to identify physician, patient, encounter, and billing characteristics associated with the positive predictive value (PPV) of case definitions for 5 syndromes (fever, gastrointestinal, neurological, rash, and respiratory (including influenza-like illness)).
\end{abstract}

Methods: The study sample comprised 4,330 syndrome-positive visits from the claims of 1,098 randomly-selected physicians working in Quebec, Canada in 2005-2007. For each visit, physician-facilitated chart review was used to assess whether the same syndrome was present in the medical chart (gold standard). We used multivariate logistic regression analyses to estimate the association between claim-chart agreement about the presence of a syndrome and physician, patient, encounter, and billing characteristics.

Results: The likelihood of the medical chart agreeing with the physician claim about the presence of a syndrome was higher when the treating physician had billed many visits for the same syndrome recently (OR $\mathrm{R}_{\text {per }} 10$ visit, 1.05; $95 \% \mathrm{Cl}, 1.01-1.08)$, had a lower workload ( $\mathrm{OR}_{\text {per }} 10$ claims, $\left.0.93 ; 95 \% \mathrm{Cl}, 0.90-0.97\right)$, and when the patient was younger

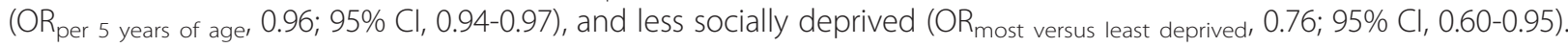

Conclusions: Many physician, patient, encounter, and billing characteristics associated with the PPV of surveillance case definition are accessible to public health, and could be used to reduce false-positive alerts by surveillance systems, either by focusing on the data most likely to be accurate, or by adjusting the observed data for known biases in diagnosis reporting and performing surveillance using the adjusted values.

\section{Background}

Syndromic surveillance systems were adopted promptly in the wake of $9 / 11$ amidst concerns of bioterrorism; their primary purpose was to detect disease outbreaks and bioterrorism events rapidly. To ensure that no outbreak would be missed, syndromic surveillance systems were initially designed to alert at very low thresholds. As a consequence of this design, syndromic surveillance

\footnotetext{
* Correspondence: genevieve.cadieux@mail.mcgill.ca

+ Contributed equally

'Department of Epidemiology and Biostatistics, McGill University, 1020 Pine Avenue West, Montreal, QC, H3A 1A2, Canada

Full list of author information is available at the end of the article
}

systems' usefulness for public health has been stymied by high rates of false-alerts $[1,2]$. Few have attempted to improve the accuracy of syndromic surveillance systems, and they have done so either by modifying statistical outbreak detection algorithms [3-5] or by using different data sources [6,7].

In contrast, in chronic disease monitoring, investigators have identified several factors that predict the accuracy of case definitions based on diagnoses in administrative data [8-16]. These studies have enabled a new generation of advanced methods for disease surveillance to be created that incorporate these predictors

\section{Biomed Central}

(c) 2012 Cadieux et al; licensee BioMed Central Ltd. This is an Open Access article distributed under the terms of the Creative Commons Attribution License (http://creativecommons.org/licenses/by/2.0), which permits unrestricted use, distribution, and reproduction in any medium, provided the original work is properly cited. 
into novel case detection methods. As a result, there has been significant improvement in case definition accuracy in chronic disease [17-20]. Specifically, these investigators found that characteristics of the physician (e.g., workload [21]), patient (e.g., comorbidity [8,9,22]), encounter (e.g., emergency admission [11]), and healthcare site (e.g., hospital volume [12]) were associated with the accuracy of case definitions based on administrative data (see Additional file 1 for summary review). Similar factors may influence the accuracy of syndromic surveillance case definitions. However, to date, no one has attempted to identify predictors of syndromic surveillance case definition accuracy. Building on the findings from chronic disease monitoring, we anticipate that the following physician, patient, encounter, and billing characteristics may be predictive of the accuracy of syndromic surveillance case definitions based on administrative data.

\section{Hypothesized predictors of the accuracy of syndromic surveillance case definitions based on diagnoses in administrative data \\ Physician characteristics}

Greater experience appears to be associated with lower accuracy of billing diagnosis [21] and diagnostic coding [23], perhaps because more experienced physicians are less likely to use reference materials to inform their coding [23]. As compared to generalists, specialists see a narrower segment of the patient population for a subset of health conditions; they likely use fewer diagnostic codes and may therefore have better billing diagnosis accuracy. Several other physician characteristics may also be relevant; physician gender and language are associated with several practice style indicators, including physician-patient communication [24-27], and may be associated with billing diagnosis accuracy.

\section{Patient characteristics}

Treating more complex patients likely requires more working memory and increases physician cognitive load [28], and thus greater patient complexity may negatively affect billing diagnosis accuracy. Indicators of patient complexity including age $[8,10,12,14,20,22,29]$, comorbidity $[8,9,30]$, socioeconomic status $[22,29]$, and health services utilization $[9,10]$ have been shown to impact the accuracy of case definitions for chronic diseases. Patient gender [8] has also been shown to influence the accuracy of case definitions, perhaps through patientphysician communication [24-27].

\section{Encounter characteristics}

The context for the clinical encounter influences how much time and what resources are available for billing, and likely impacts diagnostic data accuracy. Prior studies suggest that physician errors in diagnosis vary by type of health condition treated [15], healthcare site [15], and physician workload [21]. Weekend medical encounter are more likely to be limited to a specific acute or urgent health complaint; therefore, diagnoses for those encounters may be more accurate, particularly for infectious disease. Similarly, encounters may be more focused and claim diagnosis accuracy may be better when the physician is not/less familiar with the patient. Previous studies have shown that rare diagnoses in administrative data are more likely to be erroneous than common ones [31,32]; therefore, health conditions encountered often by physician are expected to be recorded more accurately in claims. Through a similar mechanism, syndromes that undergo seasonal variation are expected to be more accurately recorded in claims during 'peak season'.

\section{Billing practices}

No prior study has examined the relationship between billing practices and billing diagnosis accuracy; however, several attributes of billing practices likely influence the accuracy of diagnoses in administrative data. Accuracy is expected to be higher when the treating physician does the billing, as compared to clerical staff, because the treating physician has detailed knowledge of the case. Billing diagnoses that are automatically abstracted from the 'reason for visit' field of an electronic medical record are expected to be more accurate than billing diagnoses resulting from parallel manual data entry for billing purposes. Billing volume may also be associated with diagnostic coding accuracy. The proportion of billed visits with missing or unspecified diagnoses likely reflects attention to diagnostic coding, and may be associated with accuracy of diagnoses in administrative data. The breadth of diagnostic codes used by a physician likely reflects the scope of health conditions treated; a narrower scope of practice may be associated with more accurate diagnostic coding.

Whereas some of the previously identified predictors of case definition accuracy may be specific to certain chronic diseases (e.g., older age being associated with better case definition accuracy for chronic diseases that are more prevalent among older adults, such as dementia [29], osteoporosis [17], and osteoarthritis [20]) these studies provide clues as to what types of factors may predict the accuracy of syndromic surveillance case definitions. The objective of the present study was to evaluate whether or not the aforementioned physician, patient, encounter, and billing characteristics are associated with the positive predictive value (PPV) of syndromic surveillance case definitions based on diagnoses in physician claims.

\section{Methods \\ Context}

This study was conducted in the province of Quebec, Canada, where universal health coverage is provided 
through the provincial health insurance plan. Similar to health maintenance organizations and medical provider networks, each Canadian province maintains a population-based registry of insured persons and claims for all physician visits remunerated on a fee-for-service basis. The registrant database includes patient first and last name, sex, date of birth, unique lifelong medical insurance identifier, and 6-digit postal code, the latter enabling linkage to census information by geographic area of residence. Physician claims include information on the principal diagnosis for the visit (one diagnosis per claim), medical procedure, visit date, and clinic type and location. All claims also record unique physician and patient identifiers that can be used to create longitudinal histories of healthcare use. In the province of Quebec, 99\% of residents have provincial health insurance, and $85-95 \%$ of medical visits are remunerated on a fee-for-service basis [33].

\section{Study design and population}

In a prior study assessing the accuracy of syndrome definitions based on diagnoses in physician claims [31], we randomly selected a cohort of 3,600 physicians who were practicing in the fee-for-service system in the province of Quebec in 2005-2007, and who were likely to provide firstcontact care. In 2005-2007, these 3,600 study physicians billed for over 20 million visits by 4.8 million patients $(61 \%$ of the province's population) from their community-based practices. For each physician, we selected a stratified random sample of 5 visits with a syndrome-positive diagnosis in the claim, i.e., 1 visit for each of 5 syndromes of public health importance [34]: fever, gastrointestinal, neurological, rash, and respiratory, including influenza-like illness (ILI), large-group definition [35]. The present study is based on the cohort of 1,098 physicians (participation rate of $33.7 \%$ ) who were eligible and consented to provide medical chart information, and 4,330 of their visits with a syndrome-positive claim diagnosis [31].

\section{Outcome measure}

For each visit with a syndrome-positive diagnosis in the physician claim, we assessed whether the same syndrome was documented in the medical chart. Medical chart data was retrieved using a previously described physician-facilitated chart review methodology [36].

\section{Potential predictors of the accuracy of syndromic surveillance case definitions based on physician claim diagnoses \\ Physician characteristics}

Physician gender and language (French or English) were obtained from the provincial health insurance agency. Years since licensure was calculated by subtracting the year of licensure, which was obtained from the provincial medical regulatory authority, from the year of the syndrome-positive visit. Physician specialty was obtained from the provincial health insurance agency.

\section{Patient characteristics}

Patient gender was obtained from the registrant database. Patient age on October $1^{\text {st }}$ of the study year when the visit took place was obtained from the provincial health services agency. For each patient, complexity was assessed by the Charlson Comorbidity Index [37], which was computed using diagnoses in claims billed by all physicians seen during the year preceding the visit, as well as the number of ambulatory care visits in the previous year. Material and social deprivation indices, developed by the Quebec National Public Health Institute $[38,39]$, were calculated for each patient using Statistics Canada's 2006 census data. The material deprivation index summarizes information on the proportion of persons who have no high school diploma, the proportion of persons employed, and the average income in the patient's postal code area of residence. The social deprivation index summarizes information on the proportion of single-parent families, the proportion of persons living alone, and the proportion of persons separated, divorced, or widowed in the patient's 6-digit postal code area of residence.

\section{Encounter characteristics}

Syndrome type (fever, gastrointestinal, neurological, rash, and respiratory including ILI) was derived from the from physician claim diagnosis. The type of clinic was obtained from the physician claim and categorized as private clinic, community health center, or hospital ambulatory care clinic. The geographic location of the clinic was categorized as urban or rural based on the clinic's postal code. The day of the week and season during which the encounter took place was derived from the encounter date in the physician claim. As an indicator of syndrome frequency, the number of visits for the same syndrome billed by the study physician in the previous 30 days was calculated from each physician's claims. Physician workload was calculated as the number of physician claims on the day of the encounter, which reflects both the number of patients seen and the complexity of their care. Physician familiarity with the patient was assessed by determining whether or not the physician had treated the patient in the previous year.

\section{Billing practices}

The type of billing software used and what person entered the diagnostic code in the claim were obtained through a telephone interview with the physician [31]. Physicians' annual billing volume was calculated as the number of distinct claims billed by a physician during the study year when the syndrome-positive visit occurred. The percent of visits with a missing or unspecified diagnostic code was calculated as the total number of visits without any 
diagnostic code or with a diagnostic code of 'V999' (unspecified), divided by the total number of visits billed by the physician during the study year, multiplied by 100 . The number of distinct diagnostic codes used was calculated as the number of distinct diagnostic codes used among all claims billed during the study year when the syndromepositive visit occurred.

\section{Statistical methods}

Multivariable logistic regression analyses for clustered data were performed using generalized estimating equations (GEE) to estimate the association between the presence or absence of the syndrome in the medical chart (binary dependent variable) for a given visit with a syndrome-positive diagnosis in the physician claim, and physician characteristics, billing practices, patient characteristics, and encounter characteristics (SAS Version 9.2, SAS Institute Inc., Cary, NC). The visit was the unit of analysis, and visits were clustered within study physicians (there was only 1 visit per patient). Based on the assumption that physician diagnostic coding and billing patterns may change over time, visits were ordered chronologically, and a first-order autoregressive correlation structure of residuals was used to account for clustering. A 2-sided test with a p-value of 0.05 was used to assess statistical significance. In the main analyses, physician time since licensure, billing characteristics, and patient age, health services utilization, and Charlson comorbidity index were modelled as continuous variables, assuming the linearity of their association with the logit of the probability of the presence or absence of the syndrome in the medical chart. In sensitivity analyses, to account for possibly non-linear relationships, continuous variables were categorized into quartiles and modelled through three dummy indicators with the lowest quartile as the reference; we also tested the statistical significance of the quadratic component.

\section{Ethics review}

The research protocol for this study was reviewed and approved by the McGill University Institutional Review Board, the Quebec privacy commission, the Quebec health insurance agency, and the Quebec medical regulatory authority.

\section{Results}

Of 4,330 visits with a syndrome-positive diagnosis in the physician claim, 2,967 (68.5\%) visits accurately represented the primary reason for the visit when compared to the medical chart.

\section{Physician characteristics}

The PPV of syndrome definitions based on physician claim diagnoses decreased by $4 \%$ with every 5 additional years since medical licensure $\left(\mathrm{OR}_{\text {per }} 5\right.$ years, $0.96 ; 95 \%$ CI, 0.92-1.00) (Table 1). As compared to general practitioners, internists and general surgeons had $41 \%$ poorer PPV (OR, 0.59; 95\% CI, 0.35-0.98). Physician gender and language were not significantly associated with the PPV of syndrome definitions based on physician claim diagnoses.

\section{Patient characteristics}

The PPV of syndrome definitions based on physician claim diagnoses was much poorer for older patients than for younger ones, with the PPV decreasing by $4 \%$ with every additional 5 years of patient age $\left(\mathrm{OR}_{\text {per }} 5\right.$ years, 0.96; 95\% CI, 0.94-0.97) (Table 2). Whereas patient comorbidity was negatively associated with the PPV in

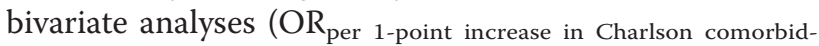
ity index $0.92 ; 95 \% \mathrm{CI}, 0.86-0.97)$, the association was no longer significant when the model was adjusted for patient age $\left(\mathrm{OR}_{\text {per 1-point increase in Charlson comorbidity index }}\right.$ 0.98; 95\% CI, 0.92-1.05). Similarly, health services utilization was significantly and negatively associated with the PPV $\left(\mathrm{OR}_{\text {per additional visit }}\right.$ 0.99; 95\% CI, 0.98-0.99), but the association did not remain statistically significant in multivariate analyses. The PPV of syndrome definitions was significantly lower for patients in the highest quintile of social deprivation $\left(\mathrm{OR}_{\text {most versus least }}\right.$ deprived, $0.76 ; 95 \% \mathrm{CI}, 0.60-0.95$ ), as compared to those in the least socially deprived quintile. The PPV of syndrome definitions was lower among patients with the most material wealth (i.e., patients in the least materially deprived quintile) as compared to patients with more

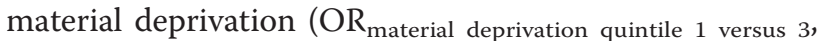
1.44, 95\% CI, 1.15-1.81). Patient gender was not significantly associated with the PPV of syndrome definitions.

\section{Encounter characteristics}

Fever syndrome had the lowest PPV of all syndromes studied; gastrointestinal syndrome (OR, 1.72; 95\% CI, 1.36-2.16), neurological syndrome (OR, 1.38; $95 \% \mathrm{CI}$, 1.11-1.72), rash syndrome (OR, 1.89; 95\% CI, 1.51-2.37), respiratory syndrome (OR, 1.66; 95\% CI, 1.29-2.14), and ILI (OR, 2.68; 95\% CI, 2.06-3.48), all had significantly higher PPV than fever syndrome (Table 3 ). With respect to physician workload, the PPV of syndrome definitions decreased by $7 \%$ with every 10 additional claims on the day of the encounter $\left(\mathrm{OR}_{\text {per }} 10\right.$ claims, 0.93 ; $95 \% \mathrm{CI}, 0.90$ 0.97). The PPV of syndrome definitions improved by $5 \%$ with every 10 visits billed by the study physician for the same syndrome in the previous month $\left(\mathrm{OR}_{\text {per }} 10\right.$ visits, 1.05; 95\% CI, 1.01-1.08). With respect to seasonality, the PPV of syndrome definitions was significantly better in spring, as compared to winter (OR, 1.29; 95\% CI, 1.071.57); this association seemed to be strongest for fever syndrome (Additional file 2). Whereas the PPV of 
Table 1 Physician characteristics associated with accuracy of syndrome definitions based on physician claims (OR $>1.00$ means the encounter characteristic increased the PPV of the syndrome definition, OR $<1.00$ means the encounter characteristic reduced the PPV)

\begin{tabular}{|c|c|c|c|c|c|c|c|c|c|c|c|c|}
\hline \multirow{3}{*}{ Physician characteristics } & \multicolumn{6}{|c|}{$\begin{array}{l}\text { No. visits with a syndrome-positive } \\
\text { physician claim }\end{array}$} & \multicolumn{3}{|c|}{$\begin{array}{l}\text { Bivariate regression } \\
\text { analysis }\end{array}$} & \multicolumn{3}{|c|}{$\begin{array}{c}\text { Multivariate regression } \\
\text { analysis }^{1}\end{array}$} \\
\hline & \multicolumn{2}{|c|}{$\begin{array}{c}\text { Syndrome- } \\
\text { positive in the } \\
\text { chart } \\
(\mathrm{N}=2,967)\end{array}$} & \multicolumn{2}{|c|}{$\begin{array}{c}\text { Syndrome- } \\
\text { negative in the } \\
\text { chart } \\
(\mathrm{N}=1,363)\end{array}$} & \multicolumn{2}{|c|}{$\begin{array}{c}\text { Total } \\
(\mathrm{N}= \\
4,330)\end{array}$} & \multirow[t]{2}{*}{ OR } & \multirow[t]{2}{*}{$95 \% \mathrm{Cl}$} & \multirow[t]{2}{*}{$P$ value } & \multirow[t]{2}{*}{ OR } & \multirow[t]{2}{*}{$95 \% \mathrm{Cl}$} & \multirow[t]{2}{*}{$P$ value } \\
\hline & No. & $\%$ & No. & $\%$ & No. & $\%$ & & & & & & \\
\hline \multicolumn{13}{|l|}{ Gender: } \\
\hline Female & 1,164 & 39.2 & 523 & 38.4 & 1,687 & 39.0 & Ref. & Ref. & Ref. & Ref. & Ref. & Ref. \\
\hline Male & 1,803 & 60.8 & 840 & 61.6 & 2,643 & 61.0 & 0.97 & $(0.83,1.12)$ & 0.64 & 1.13 & $(0.96,1.33)$ & 0.13 \\
\hline \multicolumn{13}{|l|}{ Preferred language: } \\
\hline French & 2,743 & 92.5 & 1,253 & 91.9 & 3,996 & 92.3 & Ref. & Ref. & Ref. & Ref. & Ref. & Ref. \\
\hline English & 224 & 7.5 & 110 & 8.1 & 334 & 7.7 & 0.93 & $(0.69,1.25)$ & 0.63 & 0.94 & $(0.69,1.26)$ & 0.66 \\
\hline \multicolumn{13}{|l|}{ Specialty: } \\
\hline General practice & 2,721 & 91.7 & 1,246 & 91.4 & 3,967 & 91.6 & Ref. & Ref. & Ref. & Ref. & Ref. & Ref. \\
\hline Pediatrics & 203 & 6.8 & 75 & 5.5 & 278 & 6.4 & 1.24 & $(0.88,1.77)$ & 0.22 & 0.83 & $(0.57,1.20)$ & 0.33 \\
\hline \multirow[t]{2}{*}{ Internal medicine or general surgery } & 43 & 1.5 & 42 & 3.1 & 85 & 2.0 & 0.46 & $(0.31,0.69)$ & $<0.001$ & 0.59 & $(0.35,0.98)$ & 0.04 \\
\hline & Mean & SD & Mean & SD & Mean & SD & & & & & & \\
\hline Years since licensure (per 5 years) & 22.9 & 9.2 & 23.7 & 9.6 & 23.1 & 9.4 & 0.95 & $(0.92,0.99)$ & 0.02 & 0.96 & $(0.92,1.00)$ & 0.04 \\
\hline
\end{tabular}

syndrome definitions was better for weekend visits as compared to weekday visits in the bivariate analysis (OR, 1.42, 95\% CI, 1.03-1.95), this finding was not statistically significant in the multivariate analysis. Type of clinic and geographic location of the clinic were not significantly associated with the PPV of syndrome definitions based on diagnoses in physician claims.

\section{Billing practices}

Several billing softwares were significantly associated with syndrome definition PPV (Table 4). Purkinje billing software, which abstracted the billing diagnosis from the electronic medical record in an automated manner, had a higher PPV than Soft Informatique, which required manual input of the billing diagnosis (OR, 1.29; 95\% CI, 1.05-1.59). Surprisingly, what person entered the ICD-9 diagnostic code on the billing claim was not significantly associated with the PPV of syndrome definitions. Physician annual billing volume, proportion of visits billed with a missing or unspecified diagnostic code, and number of distinct diagnostic codes used were not significantly associated with the PPV of syndrome definitions.

\section{Discussion}

We sought to identify physician, patient, encounter, and billing characteristics associated with the PPV of syndromic surveillance case definitions. Several of the predictors of syndromic surveillance case definition accuracy that we identified are readily accessible to public health departments and other organizations that routinely perform syndromic surveillance. These predictors may be used to reduce syndromic surveillance system false-positive alerts, for example, by focusing on the data most likely to be accurate or by adjusting the observed data for known biases and performing surveillance using the adjusted values; however, future research is needed to quantify the impact of our 'improved' syndrome definitions on surveillance system performance and public health practice.

Specifically, we found that visits with a syndromepositive diagnosis in physician claims were more likely to be confirmed as syndrome-positive by the medical chart when the physician was recently licensed. This finding is similar to those of other, general studies of billing diagnosis accuracy and physician experience $[21,23]$. A potential explanation for this finding is that younger physicians may be more likely to give greater attention to billing; also, more experienced physicians may be more likely to 'code from memory', which has been associated with more frequent diagnostic coding errors, as compared to coding from reference materials [23]. Similar to another study [21], we found that physicians with a higher workload on the day of the encounter had lower billing diagnosis accuracy. We also found that claims for less complex patients (i.e., younger and less socially deprived patients) were more likely to be confirmed as syndrome-positive by the medical chart, as compared to those of more complex patients. These 
Table 2 Patient characteristics associated with accuracy of syndrome definitions based on physician claims (OR $>1.00$ means the encounter characteristic increased the PPV of the syndrome definition, OR $<1.00$ means the encounter characteristic reduced the PPV)

\begin{tabular}{|c|c|c|c|c|c|c|c|c|c|c|c|c|}
\hline \multirow{3}{*}{ Patient characteristics } & \multicolumn{6}{|c|}{$\begin{array}{l}\text { No. visits with a syndrome-positive } \\
\text { physician claim }\end{array}$} & \multicolumn{3}{|c|}{$\begin{array}{l}\text { Bivariate regression } \\
\text { analysis }\end{array}$} & \multicolumn{3}{|c|}{$\begin{array}{c}\text { Multivariate regression } \\
\text { analysis }^{1}\end{array}$} \\
\hline & \multicolumn{2}{|c|}{$\begin{array}{c}\text { Syndrome- } \\
\text { positive in } \\
\text { the chart } \\
(\mathrm{N}= \\
2,967)\end{array}$} & \multicolumn{2}{|c|}{$\begin{array}{c}\text { Syndrome- } \\
\text { negative } \\
\text { in the } \\
\text { chart } \\
(\mathrm{N}= \\
1,363)\end{array}$} & \multicolumn{2}{|c|}{$\begin{array}{c}\text { Total } \\
(\mathrm{N}= \\
4,330)\end{array}$} & \multirow[t]{2}{*}{ OR } & \multirow[t]{2}{*}{$95 \% \mathrm{Cl}$} & \multirow[t]{2}{*}{$\begin{array}{c}P \\
\text { value }\end{array}$} & \multirow[t]{2}{*}{ OR } & \multirow[t]{2}{*}{$95 \% \mathrm{Cl}$} & \multirow[t]{2}{*}{$\begin{array}{c}P \\
\text { value }\end{array}$} \\
\hline & No. & $\%$ & No. & $\%$ & No. & $\%$ & & & & & & \\
\hline \multicolumn{13}{|l|}{ Sex: } \\
\hline Female & 1,810 & 61.0 & 824 & 60.5 & 2,634 & 60.8 & Ref. & Ref. & Ref. & Ref. & Ref. & Ref. \\
\hline Male & 1,157 & 39.0 & 539 & 39.5 & 1,696 & 39.2 & 0.98 & $(0.86,1.12)$ & 0.75 & 0.89 & $(0.77,1.03)$ & 0.11 \\
\hline \multicolumn{13}{|l|}{ Material deprivation index: ${ }^{2}$} \\
\hline $1^{\text {st }}$ quintile (least deprived) & 524 & 17.7 & 284 & 20.8 & 808 & 18.7 & Ref. & Ref. & Ref. & Ref. & Ref. & Ref. \\
\hline $2^{\text {nd }}$ quintile & 584 & 19.7 & 270 & 19.8 & 854 & 19.7 & 1.16 & $(0.94,1.42)$ & 0.16 & 1.18 & $(0.95,1.46)$ & 0.14 \\
\hline $3^{\text {rd }}$ quintile & 604 & 20.4 & 243 & 17.8 & 847 & 19.6 & 1.33 & $(1.08,1.64)$ & 0.01 & 1.44 & $(1.15,1.81)$ & $<0.01$ \\
\hline $4^{\text {th }}$ quintile & 581 & 19.6 & 261 & 19.1 & 842 & 19.4 & 1.21 & $(0.98,1.49)$ & 0.07 & 1.25 & $(1.01,1.55)$ & 0.04 \\
\hline $5^{\text {th }}$ quintile (most deprived) & 545 & 18.4 & 255 & 18.7 & 800 & 18.5 & 1.16 & $(0.94,1.43)$ & 0.16 & 1.21 & $(0.97,1.50)$ & 0.09 \\
\hline \multicolumn{13}{|l|}{ Social deprivation index: ${ }^{2}$} \\
\hline $1^{\text {st }}$ quintile (least deprived) & 611 & 20.6 & 251 & 18.4 & 862 & 19.9 & Ref. & Ref. & Ref. & Ref. & Ref. & Ref. \\
\hline $2^{\text {nd }}$ quintile & 574 & 19.3 & 263 & 19.3 & 837 & 19.3 & 0.90 & $(0.73,1.10)$ & 0.30 & 0.91 & $(0.74,1.13)$ & 0.41 \\
\hline $3^{\text {rd }}$ quintile & 572 & 19.3 & 251 & 18.4 & 823 & 19.0 & 0.91 & $(0.74,1.13)$ & 0.41 & 0.97 & $(0.77,1.21)$ & 0.76 \\
\hline $4^{\text {th }}$ quintile & 554 & 18.7 & 261 & 19.1 & 815 & 18.8 & 0.87 & $(0.70,1.07)$ & 0.19 & 0.88 & $(0.70,1.10)$ & 0.26 \\
\hline $5^{\text {th }}$ quintile (most deprived) & 527 & 17.8 & 287 & 21.1 & 814 & 18.8 & 0.75 & $(0.61,0.93)$ & 0.01 & 0.76 & $(0.60,0.95)$ & 0.02 \\
\hline \multicolumn{13}{|l|}{ Deprivation indices missing: } \\
\hline No & 2,838 & 95.7 & 1,313 & 96.3 & 4,151 & 95.9 & Ref. & Ref. & Ref. & Ref. & Ref. & Ref. \\
\hline \multirow[t]{2}{*}{ Yes } & 129 & 4.3 & 50 & 3.7 & 179 & 4.1 & 1.04 & $(0.73,1.49)$ & 0.83 & 1.06 & $(0.68,1.64)$ & 0.81 \\
\hline & Mean & SD & Mean & SD & Mean & SD & & & & & & \\
\hline $\begin{array}{l}\text { Age (age per } 5 \text { years is used in the regression } \\
\text { analyses) }\end{array}$ & 36.4 & 24.9 & 43.2 & 24.0 & 38.5 & 24.8 & 0.95 & $(0.93,0.96)$ & $\begin{array}{c}< \\
0.0001\end{array}$ & 0.96 & $(0.94,0.97)$ & $\begin{array}{c}< \\
0.0001\end{array}$ \\
\hline $\begin{array}{l}\text { Health services utilization (no. ambulatory care visits in } \\
\text { the previous year) }{ }^{4}\end{array}$ & 9.0 & 10.1 & 10.6 & 12.7 & 9.5 & 11.0 & 0.99 & $(0.98,0.99)$ & $\begin{array}{c}< \\
0.0001\end{array}$ & 0.99 & $(0.99,1.00)$ & 0.08 \\
\hline Charlson comorbidity index (per 1-point increase) ${ }^{4}$ & 0.38 & 0.98 & 0.49 & 1.17 & 0.42 & 1.04 & 0.92 & $(0.86,0.97)$ & $<0.01$ & 0.98 & $(0.92,1.05)$ & 0.58 \\
\hline
\end{tabular}

${ }^{1}$ Multivariate analysis adjusted for all patient characteristics in Table 2, all physician characteristics in Table 1, and all encounter characteristics in Table 3

2 The material and social deprivation indices were calculated using Statistics Canada's 2006 census data. These indices were developed by the Quebec National Public Health Institute. The material deprivation index summarizes information on the proportion of persons who have no high school diploma, the proportion of persons employed, and the average income in the patient's 6-digit postal code area of residence. The social deprivation index summarizes information on the proportion of single-parent families, the proportion of persons living alone, and the proportion of persons separated, divorced, or widowed in the patient's $6-$ digit postal code area of residence.

${ }^{3}$ On October $1^{\text {st }}$ of the study year when the visit took place. The study spanned 2 years: October 1, 2005 to September 30, 2006, and October 1, 2006 to September 30, 2007.

${ }^{4}$ Based on all medical services claims billed by all Quebec physicians (not only the 3,600 study physicians) in the year prior to the date of the syndrome-positive visit.

findings may be due to higher physician workload and greater patient complexity increasing demands on limited physician resources, taxing working memory and increasing cognitive load, thereby increasing the likelihood of physician errors, including errors in billing diagnosis. Similar to prior studies' finding that common billing diagnoses are more likely to be accurate than rare ones [31,32], we found that syndrome-positive diagnoses in physician claims were more likely to represent true-positives when the physician had billed several visits for the same syndrome recently. The observation that billing diagnosis accuracy increases with frequency of use can be explained by widely accepted theories on the effect of repetition on recall [40].

We found that billing software had a significant impact on the PPV of syndromic surveillance case definitions: billing diagnoses abstracted from the electronic medical record in an automated manner were more accurate than diagnoses input manually for billing purposes. Although this finding is based upon only a few approaches that we were able to categorize as automatic or manual, it has important implications for both 
Table 3 Encounter characteristics associated with accuracy of syndrome definitions based on physician claims (OR $>1.00$ means the encounter characteristic increased the PPV of the syndrome definition, OR $<1.00$ means the encounter characteristic reduced the PPV)

\begin{tabular}{|c|c|c|c|c|c|c|c|c|c|c|c|c|}
\hline \multirow{3}{*}{ Encounter characteristics } & \multicolumn{6}{|c|}{$\begin{array}{l}\text { No. visits with a syndrome-positive } \\
\text { physician claim }\end{array}$} & \multicolumn{3}{|c|}{$\begin{array}{c}\text { Bivariate regression } \\
\text { analysis }\end{array}$} & \multicolumn{3}{|c|}{$\begin{array}{c}\text { Multivariate regression } \\
\text { analysis }^{\top}\end{array}$} \\
\hline & \multicolumn{2}{|c|}{$\begin{array}{c}\text { Syndrome- } \\
\text { positive in } \\
\text { the chart } \\
(\mathrm{N}= \\
2,967)\end{array}$} & \multicolumn{2}{|c|}{$\begin{array}{c}\text { Syndrome- } \\
\text { negative } \\
\text { in the } \\
\text { chart } \\
(\mathrm{N}= \\
1,363)\end{array}$} & \multicolumn{2}{|c|}{$\begin{array}{c}\text { Total } \\
(\mathrm{N}= \\
4,330)\end{array}$} & \multirow[t]{2}{*}{ OR } & \multirow[t]{2}{*}{$95 \% \mathrm{Cl}$} & \multirow[t]{2}{*}{$\begin{array}{c}P \\
\text { value }\end{array}$} & \multirow[t]{2}{*}{ OR } & \multirow[t]{2}{*}{$95 \% \mathrm{Cl}$} & \multirow[t]{2}{*}{$\begin{array}{c}P \\
\text { value }\end{array}$} \\
\hline & No. & $\%$ & No. & $\%$ & No. & $\%$ & & & & & & \\
\hline \multicolumn{13}{|l|}{ Syndrome type: } \\
\hline Fever & 371 & 12.5 & 230 & 16.9 & 601 & 13.9 & Ref. & Ref. & Ref. & Ref. & Ref. & Ref. \\
\hline Gastrointestinal & 572 & 19.3 & 283 & 20.8 & 855 & 19.8 & 1.57 & $(1.25,1.97)$ & $\begin{array}{c}<< \\
0.0001\end{array}$ & 1.72 & $(1.36,2.16)$ & $\begin{array}{c}< \\
0.0001\end{array}$ \\
\hline Neurological & 608 & 20.5 & 363 & 26.6 & 971 & 22.4 & 1.29 & $(1.05,1.60)$ & 0.02 & 1.38 & $(1.11,1.72)$ & $<0.01$ \\
\hline Rash & 628 & 21.2 & 269 & 19.7 & 897 & 20.7 & 1.80 & $(1.44,2.25)$ & $\begin{array}{c}< \\
0.0001\end{array}$ & 1.89 & $(1.51,2.37)$ & $\begin{array}{c}< \\
0.0001\end{array}$ \\
\hline Respiratory & 808 & 27.2 & 241 & 17.7 & 1049 & 24.2 & 1.72 & $(1.36,2.17)$ & $\begin{array}{c}< \\
0.0001\end{array}$ & 1.66 & $(1.29,2.14)$ & $\begin{array}{c}< \\
0.0001\end{array}$ \\
\hline ILI & 555 & 18.7 & 98 & 7.2 & 653 & 15.1 & 2.98 & $(2.32,3.82)$ & $\begin{array}{c}< \\
0.0001\end{array}$ & 2.68 & $(2.06,3.48)$ & $\begin{array}{c}< \\
0.0001\end{array}$ \\
\hline \multicolumn{13}{|l|}{ Type of clinic: } \\
\hline Private clinic & 2,916 & 98.3 & 1,320 & 96.9 & 4,236 & 97.8 & Ref. & Ref. & Ref. & Ref. & Ref. & Ref. \\
\hline Community health center & 10 & 0.3 & 8 & 0.6 & 18 & 0.4 & 0.58 & $(0.14,2.35)$ & 0.45 & 0.46 & $(0.11,2.01)$ & 0.30 \\
\hline Hospital-based ambulatory clinic & 41 & 1.4 & 35 & 2.6 & 76 & 1.8 & 0.53 & $(0.30,0.93)$ & 0.03 & 0.75 & $(0.37,1.53)$ & 0.43 \\
\hline \multicolumn{13}{|l|}{ Geographic location of clinic: } \\
\hline Urban & 2,476 & 83.5 & 1,169 & 85.8 & 3,645 & 84.2 & Ref. & Ref. & Ref. & Ref. & Ref. & Ref. \\
\hline Rural & 491 & 16.6 & 194 & 14.2 & 685 & 15.8 & 1.20 & $(0.99,1.46)$ & 0.07 & 1.19 & $(0.98,1.45)$ & 0.08 \\
\hline
\end{tabular}

Physician familiarity with the patient (patient treated

by the study physician in the previous year):

\begin{tabular}{|c|c|c|c|c|c|c|c|c|c|c|c|c|}
\hline No & 1,199 & 40.4 & 475 & 34.9 & 1,674 & 38.7 & Ref. & Ref. & Ref. & Ref. & Ref. & Ref. \\
\hline Yes & 1,768 & 59.6 & 888 & 65.1 & 2,656 & 61.3 & 0.79 & $(0.69,0.91)$ & $\begin{array}{c}< \\
0.001\end{array}$ & 0.95 & $(0.82,1.11)$ & 0.53 \\
\hline \multicolumn{13}{|l|}{ Day of the week: } \\
\hline Weekday & 2,797 & 94.3 & 1,308 & 96.0 & 4,105 & 94.8 & Ref. & Ref. & Ref. & Ref. & Ref. & Ref. \\
\hline Weekend & 170 & 5.7 & 55 & 4.0 & 225 & 5.2 & 1.42 & $(1.03,1.95)$ & 0.03 & 1.28 & $(0.92,1.77)$ & 0.15 \\
\hline \multicolumn{13}{|l|}{ Season: } \\
\hline Winter $(12 / 22-03 / 20)$ & 737 & 24.8 & 339 & 24.9 & 1,076 & 24.9 & Ref. & Ref. & Ref. & Ref. & Ref. & Ref. \\
\hline Spring $(03 / 21-06 / 20)$ & 855 & 28.8 & 317 & 23.3 & 1,172 & 27.1 & 1.22 & $(1.02,1.47)$ & 0.03 & 1.29 & $(1.07,1.57)$ & 0.01 \\
\hline Summer (06/21-09/22) & 645 & 21.7 & 351 & 25.8 & 996 & 23.0 & 0.84 & $(0.70,1.01)$ & 0.06 & 0.91 & $(0.75,1.10)$ & 0.33 \\
\hline \multirow[t]{2}{*}{ Fall $(09 / 23-12 / 21)$} & 730 & 24.6 & 356 & 26.1 & 1,086 & 25.1 & 0.94 & $(0.79,1.12)$ & 0.48 & 0.97 & $(0.81,1.17)$ & 0.79 \\
\hline & Mean & SD & Mean & SD & Mean & SD & & & & & & \\
\hline $\begin{array}{l}\text { No. visits for the same syndrome billed by the study } \\
\text { physician in the previous } 30 \text { days (per } 10 \text { visits) }\end{array}$ & 4.1 & 6.7 & 4.2 & 6.2 & 4.2 & 6.6 & 1.08 & $(0.95,1.23)$ & 0.25 & 1.05 & $(1.01,1.08)$ & 0.01 \\
\hline $\begin{array}{l}\text { Physician workload: no. claims billed that day (per } 10 \\
\text { claims) }\end{array}$ & 35.1 & 17.4 & 36.5 & 21.0 & 35.5 & 18.6 & 0.96 & $(0.93,1.00)$ & 0.03 & 0.93 & $(0.90,0.97)$ & $\begin{array}{c}< \\
0.001\end{array}$ \\
\hline
\end{tabular}

\footnotetext{
${ }^{1}$ Multivariate analysis adjusted for all encounter characteristics in Table 3, all physician characteristics in Table 1, and all patient characteristics in Table 2.
}

clinical users and public health surveillance. Whereas public health surveillance previously required health practitioners to submit case reports manually, it is now becoming a process where public health agencies automatically extract relevant data from clinical information systems. Indeed, the US federal government has allotted $\$ 39$ billion to support the adoption and 'meaningful use' of electronic health records, and software 
Table 4 Billing practices associated with accuracy of syndrome definitions based on physician claims (OR $>1.00$ means the encounter characteristic increased the PPV of the syndrome definition, OR $<1.00$ means the encounter characteristic reduced the PPV)

\begin{tabular}{|c|c|c|c|c|c|c|c|c|c|}
\hline \multirow[b]{2}{*}{ Billing practices } & \multicolumn{3}{|c|}{$\begin{array}{l}\text { No. visits with a syndrome-positive } \\
\text { physician claim }\end{array}$} & \multicolumn{3}{|c|}{$\begin{array}{l}\text { Bivariate regression } \\
\text { analysis }\end{array}$} & \multicolumn{3}{|c|}{$\begin{array}{c}\text { Multivariate regression } \\
\text { analysis }^{1}\end{array}$} \\
\hline & $\begin{array}{l}\text { Syndrome- } \\
\text { positive in } \\
\text { the chart } \\
(\mathrm{N}=2,967)\end{array}$ & $\begin{array}{c}\text { Syndrome- } \\
\text { negative in } \\
\text { the chart } \\
(\mathrm{N}=1,363)\end{array}$ & $\begin{array}{l}\text { Total } \\
(\mathrm{N}=4,330)\end{array}$ & OR & $95 \% \mathrm{Cl}$ & $\begin{array}{c}P \\
\text { value }\end{array}$ & OR & $95 \% \mathrm{Cl}$ & $\begin{array}{c}P \\
\text { value }\end{array}$ \\
\hline & No. & No. & No. & & & & & & \\
\hline
\end{tabular}

What person entered the diagnostic code in the claim?

\begin{tabular}{|c|c|c|c|c|c|c|c|c|c|c|c|c|}
\hline Physician & 443 & 14.9 & 203 & 14.9 & 646 & 14.9 & Ref. & Ref. & Ref. & Ref. & Ref. & Ref. \\
\hline Secretary or nurse & 2,015 & 67.9 & 907 & 66.5 & 2,922 & 67.5 & 1.01 & $(0.82,1.26)$ & 0.91 & 0.93 & $(0.75,1.15)$ & 0.50 \\
\hline $\begin{array}{l}\text { Off-site billing company or RAMQ (i.e., paper } \\
\text { billing) }^{2}\end{array}$ & 509 & 17.2 & 253 & 18.6 & 762 & 17.6 & 0.92 & $(0.71,1.19)$ & 0.52 & 0.81 & $(0.62,1.06)$ & 0.12 \\
\hline \multicolumn{13}{|l|}{ Billing software used: } \\
\hline Soft Informatique & 715 & 24.4 & 342 & 25.4 & 1,057 & 24.8 & Ref. & Ref. & Ref. & Ref. & Ref. & Ref. \\
\hline Purkinje & 721 & 24.7 & 264 & 19.6 & 985 & 23.1 & 1.30 & $(1.07,1.60)$ & 0.01 & 1.29 & $(1.05,1.59)$ & 0.02 \\
\hline ADN Medical & 405 & 13.9 & 166 & 12.3 & 571 & 13.4 & 1.16 & $(0.90,1.49)$ & 0.24 & 1.17 & $(0.91,1.50)$ & 0.23 \\
\hline Omni-Med.com Caduceus & 250 & 8.6 & 124 & 9.2 & 374 & 8.8 & 0.96 & $(0.74,1.25)$ & 0.77 & 0.94 & $(0.72,1.24)$ & 0.67 \\
\hline Medicus MED-WIN & 123 & 4.2 & 67 & 5.0 & 190 & 4.5 & 0.87 & $(0.65,1.17)$ & 0.36 & 0.87 & $(0.64,1.17)$ & 0.35 \\
\hline Facturation.net & 73 & 2.5 & 64 & 4.8 & 137 & 3.2 & 0.55 & $(0.35,0.86)$ & 0.01 & 0.54 & $(0.34,0.85)$ & 0.01 \\
\hline ANDX Xclaim & 61 & 2.1 & 40 & 3.0 & 115 & 2.7 & 0.73 & $(0.47,1.14)$ & 0.17 & 0.70 & $(0.42,1.15)$ & 0.16 \\
\hline CareOffice & 85 & 2.9 & 30 & 2.2 & 103 & 2.4 & 1.36 & $(0.84,2.18)$ & 0.21 & 1.32 & $(0.76,2.27)$ & 0.32 \\
\hline Médifiche & 75 & 2.6 & 28 & 2.1 & 101 & 2.4 & 1.28 & $(0.81,2.02)$ & 0.29 & 1.24 & $(0.77,1.98)$ & 0.38 \\
\hline Toubib & 52 & 1.8 & 43 & 3.2 & 95 & 2.2 & 0.58 & $(0.32,1.05)$ & 0.07 & 0.53 & $(0.29,0.97)$ & 0.04 \\
\hline FMP & 57 & 2.0 & 16 & 1.2 & 73 & 1.7 & 1.71 & $(0.92,3.19)$ & 0.09 & 1.74 & $(0.90,3.34)$ & 0.10 \\
\hline Médicalc Inc. ${ }^{3}$ & 49 & 1.7 & 19 & 1.4 & 68 & 1.6 & 1.23 & $(0.61,2.47)$ & 0.57 & 1.27 & $(0.62,2.62)$ & 0.51 \\
\hline Param & 47 & 1.6 & 18 & 1.3 & 65 & 1.5 & 1.24 & $(0.67,2.29)$ & 0.49 & 1.19 & $(0.66,2.17)$ & 0.56 \\
\hline ACL Systèmes Santé & 43 & 1.5 & 20 & 1.5 & 63 & 1.5 & 1.03 & $(0.58,1.84)$ & 0.92 & 1.06 & $(0.56,2.02)$ & 0.85 \\
\hline Factura-Med & 43 & 1.5 & 17 & 1.3 & 60 & 1.4 & 1.20 & $(0.79,1.84)$ & 0.39 & 1.24 & $(0.81,1.89)$ & 0.32 \\
\hline FmedX MED-Office & 39 & 1.3 & 18 & 1.3 & 57 & 1.3 & 1.04 & $(0.48,2.25)$ & 0.92 & 0.99 & $(0.46,2.13)$ & 0.98 \\
\hline Sys-Thèmes & 24 & 0.8 & 9 & 0.7 & 33 & 0.8 & 1.27 & $(0.54,3.00)$ & 0.59 & 1.24 & $(0.55,2.77)$ & 0.61 \\
\hline Gestimed & 12 & 0.4 & 14 & 1.0 & 26 & 0.6 & 0.41 & $(0.21,0.81)$ & 0.01 & 0.45 & $(0.25,0.84)$ & 0.01 \\
\hline Salus & 10 & 0.3 & 10 & 0.7 & 20 & 0.5 & 0.48 & $(0.18,1.32)$ & 0.16 & 0.45 & $(0.14,1.44)$ & 0.18 \\
\hline Logimedic & 7 & 0.2 & 8 & 0.6 & 15 & 0.4 & 0.41 & $(0.16,1.05)$ & 0.06 & 0.39 & $(0.15,1.03)$ & 0.06 \\
\hline Medi-Go & 2 & 0.1 & 6 & 0.5 & 8 & 0.2 & 0.16 & $(0.02,1.68)$ & 0.13 & 0.15 & $(0.01,1.72)$ & 0.13 \\
\hline $\begin{array}{l}\text { Services de facturations médicales } \\
\text { informatiques }^{3}\end{array}$ & 4 & 0.1 & 3 & 0.2 & 7 & 0.2 & 0.63 & $(0.40,1.01)$ & 0.06 & 0.65 & $(0.37,1.16)$ & 0.14 \\
\hline Other $^{4}$ & 13 & 0.4 & 3 & 0.2 & 16 & 0.4 & 2.12 & $(0.71,6.29)$ & 0.18 & 1.94 & $(0.71,5.28)$ & 0.19 \\
\hline Unknown & 15 & 0.5 & 17 & 1.3 & 32 & 0.8 & 0.41 & $(0.20,0.86)$ & 0.02 & 0.48 & $(0.24,0.93)$ & 0.03 \\
\hline \multirow[t]{2}{*}{ RAMQ (i.e., paper billing)2 } & 42 & 1.4 & 17 & 1.2 & 59 & 1.4 & 1.18 & $(0.55,2.57)$ & 0.67 & 1.39 & $(0.63,3.07)$ & 0.41 \\
\hline & Mean & SD & Mean & SD & Mean & SD & & & & & & \\
\hline Annual billing volume (per 1,000 claims) & 4,913 & 2,623 & 4,913 & 2,646 & 4,913 & 2,630 & 1.00 & $(0.97,1.03)$ & 0.94 & 1.00 & $(0.97,1.04)$ & 0.91 \\
\hline $\begin{array}{l}\text { Percent of visits with a missing or unspecified } \\
\text { diagnostic code }\end{array}$ & 2.5 & 5.7 & 2.5 & 5.1 & 2.5 & 5.5 & 1.00 & $(0.99,1.02)$ & 0.91 & 1.01 & $(0.99,1.02)$ & 0.34 \\
\hline No distinct diagnostic codes used (per 100 codes) $)^{5}$ & 228 & 88 & 227 & 97 & 228 & 91 & 1.01 & $(0.94,1.10)$ & 0.76 & 1.02 & $(0.92,1.12)$ & 0.75 \\
\hline
\end{tabular}

1 Multivariate analysis adjusted for all billing practices in Table 4 and all physician characteristics in Table 1.

2 RAMQ: Régie de l'assurance maladie du Québec (provincial health agency). Few physicians submit paper billing slips (as opposed to using electronic billing software) to the provincial health agency for fee-for-service reimbursement; if they do, they are imposed a $\$ 0.50$ penalty on every paper bill submitted, and a data entry clerk at the provincial health agency must enter the diagnostic code from the paper billing slip into the RAMQ's computerized billing database (this additional step is a potential source of transcription error).

${ }^{3}$ Software developed and used solely by their namesake off-site billing company.

${ }^{4}$ Single-user billing software developed by individual physicians.

${ }^{5}$ In the study year when the visit took place. The study spanned 2 years: October 1, 2005 to September 30, 2006, and October 1, 2006 to September 30, 2007. 
purchased using these funds must support automated submission of data to public health agencies for three public health uses, including syndromic surveillance [41]. This investment presents an opportunity to improve syndromic surveillance systems by having electronic health records capture and transmit information on highly influential predictors of case definition accuracy. To this end, a working group of surveillance experts from the US Centers for Disease Control and Prevention and the International Society for Disease Surveillance recently proposed specifications for the data captured by emergency department electronic health records and transmitted to public health [42]; however, this process has yet to take place for community-based ambulatory care settings. Our study findings are directly relevant to the discussion of what data elements should be captured and transmitted by electronic health records from primary care settings to public health under the 'meaningful use' mandate.

Our study had several strengths. It was based on a large representative sample of physicians and patients. We had access to many physician, patient, encounter, and billing characteristics, which enabled us to perform a comprehensive assessment of the impact of a variety of factors on the accuracy of syndromic surveillance case definitions. Whereas some of our findings may be specific to our study population, most of our findings are likely generalizable across North American jurisdictions due to similar physician and patient populations. A limitation of our study was that the number of visits per syndrome was too small to identify predictors of case definition accuracy specific to each syndrome individually. Whereas most of the predictors of case definition accuracy that we identified would be expected to impact all syndrome definitions in a similar manner (e. g., physician workload, patient complexity), some predictors (e.g., season) may have a greater impact on some case definitions than others. Also, it should be noted that our study identified predictors of the PPV of billing diagnoses; therefore, our findings may not be directly applicable to surveillance systems that use different data, such as chief complaints from emergency departments. However, the research methodology described in this manuscript can be used to identify predictors of accuracy of other types of surveillance data.

\section{Conclusions}

Through a chart validation involving a large random sample of physicians, we have demonstrated that measurable elements of the medical encounter affect the accuracy of syndrome reports derived from physician claims. These elements, which include physician, patient, encounter, and billing characteristics, can be collected by public health departments through automated surveillance systems and used to focus or adjust analyses in order to reduce false-alerts. The rich clinical data streams becoming accessible to public health should enable the implementation of surveillance strategies that incorporate our findings. As the volume and detail of clinical data continue to increase, future research should explore how public health can harness their full breadth to further enhance the accuracy of case detection.

\section{Additional material}

Additional file 1: Table S1. Studies that have identified covariates associated with the accuracy of chronic disease case definitions based on diagnoses in administrative data.

Additional file 2: Table S2. Patient, physician, encounter, and billing characteristics associated with accuracy of syndrome definitions based on physician claims: results from bivariate regression analyses for each syndrome individually.

\section{Acknowledgements}

The authors would like to thank Jimmy Fragos for providing technical support and database management. This work was supported by the Canadian Institutes for Health Research and the McGill University Health Centre Research Institute.

\section{Author details}

${ }^{1}$ Department of Epidemiology and Biostatistics, McGill University, 1020 Pine Avenue West, Montreal, QC, H3A 1A2, Canada. ${ }^{2}$ Direction de la Santé Publique de Montréal, 1301 Sherbrooke Street East, Montreal, QC, H2L 1M3, Canada. ${ }^{3}$ Collège des Médecins du Québec, 2170 René-Lévesque Boulevard West, Montreal, QC, H3H 2T8, Canada. ${ }^{4}$ Department of Medicine, McGill University, 3655 Sir William Osler Promenade, Montreal, QC, H3G 1Y6, Canada.

\section{Authors' contributions}

All authors read and approved the final manuscript. GC collected the data, performed the data analysis, and is the primary author of the manuscript. AJ helped develop the methods and collect the data, and provided useful comments on the manuscript. ML helped develop the methods and provided useful comments on the manuscript. ND helped develop the methods, led the analysis, and provided useful comments on the manuscript. RT and DLB provided access to claims data and study subjects, helped develop the methods, oversaw the analysis, and provided useful comments on the manuscript.

\section{Competing interests}

The authors declare that they have no competing interests.

Received: 5 September 2011 Accepted: 8 March 2012 Published: 8 March 2012

\section{References}

1. Fricker RD Jr: Some methodological issues in biosurveillance. Stat Med 2011, 30:403-415.

2. Reingold A: If Syndromic Surveillance Is the Answer, What Is the Question? Biosecur Bioterror 2003, 1:77-81.

3. Hutwagner LC, Thompson WW, Seeman GM, Treadwell T: A simulation model for assessing aberration detection methods used in public health surveillance for systems with limited baselines. Stat Med 2005, 24:543-550.

4. Buckeridge DL, Burkom H, Campbell M, Hogan WR, Moore AW: Algorithms for rapid outbreak detection: a research synthesis. J Biomed Inform 2005, 38:99-113. 
5. Jackson ML, Baer A, Painter I, Duchin J: A simulation study comparing aberration detection algorithms for syndromic surveillance. BMC Med Inform 2007, 7:6-17.

6. Reis BY, Mandl KD: Syndromic surveillance: The effects of syndrome grouping on model accuracy and outbreak detection. Ann Emerg Med 2004, 44:235-241.

7. South BR, Chapman WW, DeLisle S, Shen S, Kalp E, Perl T, et al: Optimizing a Syndromic Surveillance Text Clasifier for Influenza-Like Illness: Does Document Source Matter?, In: American Medical Informatics Association 2008 Symposium Proceedings, 692-696.

8. van Walraven C, Austin PC, Manuel D, Knoll G, Jennings A, Forster AJ: The usefulness of administrative databases for identifying disease cohorts is increased with a multivariate model. J Clin Epidemiol 2010, 63:1332-1341.

9. Singh JA: Discordance Between Self-report of Physician Diagnosis and Administrative Database Diagnosis of Arthritis and Its Predictors. J Rheumatol 2009, 36:2000-2008.

10. Taylor DH, Fillenbaum GG, Ezell ME: The accuracy of medicare claims data in identifying Alzheimer's disease. J Clin Epidemiol 2002, 55:929-937.

11. Maclntyre CR, Ackland MJ, Chandraraj EJ, Pilla JE: Accuracy of ICD-9-CM codes in hospital morbidity data, Victoria: implications for public health research. Aust N Z J Public Health 1997, 21:477-482

12. Jollis JG, Ancukiewicz M, Delong ER, Pryor DB, Muhlbaier LH, Mark DB: Discordance of Databases Designed for Claims Payment Versus Clinical Information-Systems-Implications for Outcomes Research. Ann Intern Med 1993, 119:844-850

13. Losina E, Barrett J, Baron JA, Katz JN: Accuracy of Medicare claims data for rheumatologic diagnoses in total hip replacement recipients. J Clin Epidemiol 2003, 56:515-519.

14. Andrade SE, Gurwitz JH, Chan KA, Donahue JG, Beck A, Boles M, et al: Validation of diagnoses of peptic ulcers and bleeding from administrative databases: A multi-health maintenance organization study. J Clin Epidemiol 2002, 55:310-313.

15. Peabody JW, Luck J, Jain S, Bertenthal D, Glassman P: Assessing the accuracy of administrative data in health information systems. Medical Care 2004, 42:1066-1072.

16. Kostylova A, Swaine B, Feldman D: Concordance between childhood injury diagnoses from two sources: an injury surveillance system and a physician billing claims database. Inj Prev 2005, 11:186-190.

17. Lix LM, Yogendran MS, Leslie WD, Shaw SY, Baumgartner R, Bowman C, et al: Using multiple data features improved the validity of osteoporosis case ascertainment from administrative databases. J Clin Epidemio/ 2008, 61:1250-1260

18. Szumski NR, Cheng EM: Optimizing Algorithms to Identify Parkinson's Disease Cases Within an Administrative Database. Mov Disord 2009, 24:51-56.

19. Love TJ, Cai T, Karlson EW: Validation of Psoriatic Arthritis Diagnoses in Electronic Medical Records Using Natural Language Processing. Semin Arthritis Rheum 2010, 40:413-420.

20. Gabriel SE, Crowson CS: OFallon WM: A mathematical model that improves the validity of osteoarthritis diagnoses obtained from a computerized diagnostic database. J Clin Epidemiol 1996, 49:1025-1029.

21. Studney DR, Hakstian AR: A Comparison of Medical Record with Billing Diagnostic Information Associated with Ambulatory Medical-Care. Am J Public Health 1981, 71:145-149.

22. McClish DK, Penberthy L, Whittemore M, Newschaffer C, Woolard D, Desch CE, et al: Ability of Medicare claims data and cancer registries to identify cancer cases and treatment. Am J Epidemiol 1997, 145:227-233.

23. Farzandipour M, Sheikhtaheri A, Sadoughi F: Effective factors on accuracy of principal diagnosis coding based on International Classification of Diseases, the 10th revision (ICD-10). Int J Inf Manage 2010, 30:78-84.

24. Hall JA, Roter DL: Patient gender and communication with physicians: results of a community-based study. Womens Health 1995, 1:77-95

25. Schmittdiel J, Grumbach K, Selby JV, Quesenberry CP: Effect of physician and patient gender concordance on patient satisfaction and preventive care practices. J Gen Intern Med 2000, 15:761-769.

26. Roter DL, Hall JA, Aoki Y: Physician gender effects in medical communication-A meta-analytic review. JAMA 2002, 288:756-764

27. Hall JA, Roter DL: Do patients talk differently to male and female physicians? A meta-analytic review. Patient Educ Couns 2002, 48:217-224.

28. Chandler P, Sweller J: Cognitive load theory and the format of instruction. Cogn Instr 1991, 8:293-332.
29. Ostbye T, Taylor DH, Clipp EC, Van Scoyoc L, Plassman BL: Identification of dementia: Agreement among national survey data, medicare claims, and death certificates. Health Serv Res 2008, 43:313-326.

30. Muhajarine N, Mustard C, Roos LL, Young TK, Gelskey DE: Comparison of survey and physician claims data for detecting hypertension. J Clin Epidemiol 1997, 50:711-718

31. Cadieux G, Buckeridge DL, Jacques A, Libman M, Dendukuri N: Accuracy of Syndrome Definitions Based on Diagnoses in Physician Claims. BMC Public Health 2011, 11:17-26.

32. Sickbert-Bennett EE, Weber DJ, Poole C, MacDonald PDM, Maillard JM: Utility of International Classification of Diseases, Ninth Revision, Clinical Modification Codes for Communicable Disease Surveillance. Am J Epidemiol 2010, 172:1299-1305.

33. Regie de l'assurance-maladie du Quebec. Statistiques Annuelles 2000, 46-48, Regie de l'assurance-maladie du Quebec. Ref Type: Report.

34. Centers for Disease Control and Prevention. Syndrome Definitions for Diseases Associated with Critical Bioterrorism-associated Agents 1-29[http:// www.bt.cdc.gov/surveillance/syndromedef/], 10-23-2003. Ref Type: Report.

35. Marsden-Haug N, Foster VB, Gould PL, Elbert E, Wang HL, Pavlin JA: Codebased syndromic surveillance for influenzalike illness by international classification of diseases, ninth revision. Emerg Infect Dis 2007, 13:207-216.

36. Cadieux G, Buckeridge DL, Jacques A, Libman M, Dendukuri N: Accuracy of Syndrome Definitions Based on Diagnoses in Physician Claims. In BMC Public Health. Volume 11. BioMed Central; 2011(17).

37. Romano PS, Roos LL, Jollis JG: Adapting A Clinical Comorbidity Index for Use with Icd-9-Cm Administrative Data-Differing Perspectives. J Clin Epidemiol 1993, 46:1075-1079.

38. Pampalon R, Raymond G: A Deprivation Index for Health and Welfare Planning in Quebec. Chronic Dis Can 2000, 21:113-122.

39. Pampalon R, Hamel D, Gamache P, Raymond G: A deprivation index for health planning in Canada. Chronic Dis Can 2009, 29:178-191.

40. Richardson-Klavehn A, Bjork RA: Measures of Memory. Annu Rev Psychol 1988, 39:475-543

41. Blumenthal D, Tavenner M: The "Meaningful Use" Regulation for Electronic Health Records. N Engl J Med 2010, 363:501-504.

42. Centers for Disease Control and Prevention. PHIN Messaging Guide for Syndromic Surveillance 2011, 1-127[http://www.cdc.gov/phin/library/guides/ Syndromic_Surveillance_Implementation_Guide_Release_1_4.pdf], Centers for Disease Control and Prevention. Ref Type: Report.

\section{Pre-publication history}

The pre-publication history for this paper can be accessed here: http://www.biomedcentral.com/1471-2458/12/166/prepub

doi:10.1186/1471-2458-12-166

Cite this article as: Cadieux et al:: Patient, physician, encounter, and billing characteristics predict the accuracy of syndromic surveillance case definitions. BMC Public Health 2012 12:166.

\section{Submit your next manuscript to BioMed Central and take full advantage of:}

- Convenient online submission

- Thorough peer review

- No space constraints or color figure charges

- Immediate publication on acceptance

- Inclusion in PubMed, CAS, Scopus and Google Scholar

- Research which is freely available for redistribution

Submit your manuscript at www.biomedcentral com/submit
C Biomed Central 